\title{
Registros de coda nasal no primeiro ano do ensino fundamental
}

\author{
Simone Rizzatto Albertini \\ Universidade Estadual Paulista "Júlio de Mesquita Filho" (UNESP), \\ São José do Rio Preto, São Paulo, Brasil \\ simone.rizzatto@gmail.com
}

DOI: http://dx.doi.org/10.21165/el.v46i2.1751

\begin{abstract}
Resumo
Neste estudo, busca-se traçar trajetos que possam ser típicos do processo de aquisição de escrita de sílabas com coda nasal do Português. Foram observados registros e não-registros da coda nasal em produções escritas ao longo do primeiro ano do Ensino Fundamental, em escola particular. Identificamos a tendência de os sujeitos grafarem sílabas CV não-convencionalmente ("AVK" para "avenca") nas primeiras produções e passarem a registrar a sílaba CV ("BEGALA" para "bengala"), ainda no primeiro semestre do ano letivo. Já no segundo semestre, a tendência foi a de não haver registros de sílabas CV e haver registros não-convencionais da coda nasal ("CEN" para "quem") que flutuam com registros convencionais dessa coda ("VENTO"). Ao final do primeiro ano letivo, todos os oito sujeitos analisados flutuam entre grafar e não grafar convencionalmente a coda nasal, evidenciando a aquisição da sílaba complexa, embora ainda não tenham dominado a convenção ortográfica do seu registro.
\end{abstract}

Palavras-chave: coda nasal; sílaba; ortografia; língua portuguesa; ensino fundamental.

\section{Registration of nasal coda in the first year of elementary school}

\begin{abstract}
In this study, we had identified typical differences concerning the number of occurrences of nonregistry of nasality and of unconventional nasality written registries of Portuguese language, which were performed by students of first year of Elementary School in a private school. In a brief way, we had identified the tendency of the subjects in not writing the syllables CV conventionally ("AVK" for "avenca") in their first production and then, in started registering the syllable CV ("BEGALA" for "bengala"), still in the first half of the school year. In the second half, we identified a tendency of not registering the syllables $\mathrm{CV}$ and of unconventional registries of nasal coda ("CEN" for "quem"), which blend with the conventional registry of this coda ("VENTO"). At the end of the first school year, all the eight subjects analyzed stayed between writing and not writing the nasal coda, thus highlighting the acquisition of the complex syllable with coda, although not still mastering the spelling convention registration.
\end{abstract}

Keywords: nasal coda; syllable; spelling; Portuguesanguage; elementary school.

\section{Introdução}

Este trabalho tem como objeto de estudo grafias de sílabas com coda nasal produzidas por crianças em processo de alfabetização, matriculadas no primeiro ano do ensino fundamental, na cidade de São José do Rio Preto (SP). Na literatura, encontramse estudos sobre grafias não-convencionais da coda silábica feitos com base em textos escritos por crianças em fase inicial do processo de alfabetização em outra região 
geográfica (MIRANDA, 2009) do país, mas não há estudos sobre o tema com dados produzidos por alunos na região do interior paulista, como o que ora desenvolvemos. Há estudos sobre o tema realizados na mesma região com base em textos produzidos por jovens e adultos (BORDUQUI, 2010). Este trabalho permitirá, em futuro próximo, comparar resultados obtidos a partir de estudos de diferentes regiões do país, por um lado, e resultados entre crianças e adultos, por outro lado.

Este artigo se justifica na medida em que poderá contribuir com reflexões teóricas acerca da aquisição da escrita, particularmente, sobre características da sílaba enquanto unidade linguística relevante para analisar produções escritas em contexto formal de alfabetização. Também poderá contribuir, de modo mais amplo, com reflexões relacionadas à prática pedagógica de professores alfabetizadores no que tange às dificuldades que enfrentam os alunos para compreender o sistema de escrita. O estudo sobre as grafias de coda nasal exige a reflexão sobre a sílaba, visto que esta é uma unidade linguística em função da qual se organizam os segmentos e, em certa medida, direciona o trabalho de alfabetização em contexto escolar. Por meio deste trabalho, demonstra-se a importância da posição que cada segmento ocupa na estrutura silábica durante o processo de aquisição de escrita.

Parte-se da hipótese de que a nasalidade é um traço associado ao nó supralaríngeo de segmento em coda silábica, como propõe Wetzels (1988). No que diz respeito aos erros ortográficos encontrados nas escritas iniciais dos alunos, Miranda (2009) afirma ser uma importante fonte de estudos para aqueles que se dispõem a abordar o complexo processo de aquisição da escrita. Ainda de acordo com a autora, os erros produzidos pelas crianças oferecem pistas sobre as hipóteses formuladas pelos aprendizes quando se deparam com o sistema de escrita que estão prestes a adquirir.

Portanto, o objetivo geral é descrever como crianças no primeiro ano do Ensino Fundamental lidam com a complexidade da grafia de sílabas com coda nasal. E, no caso de haver registro da nasal em coda, o objetivo específico é observar se a registram convencionalmente ou não convencionalmente; no caso de registros não convencionais, pretende-se (i) identificar se a marca gráfica que representa a nasalidade distintiva se dá na coda, na vogal ou em toda a rima silábica; e (ii) analisar diferentes possibilidades de registros gráficos da nasalidade em Português que se mostrariam relevantes na grafia de sílabas com coda nasal na fase inicial de aquisição da escrita.

Os dados analisados foram extraídos de 17 produções escritas de oito alunos, sendo classificado em dois grupos: quatro estudantes do sexo masculino e quatro do sexo feminino. Todos os alunos eram, na época da coleta, regularmente matriculados no primeiro ano do ensino fundamental, em processo formal de alfabetização no período vespertino. Os dados foram coletados no ano de 2014, na unidade escolar Cooperativa Regional de Educação e Cultura Albert Sabin - COOPEC - que é vinculada ao sistema privado de ensino, inserida em um bairro de classe média/alta da cidade de São José do Rio Preto (SP), com horário de funcionamento no período diurno. As produções selecionadas foram produzidas sem interferência da professora no processo de registro escrito. As propostas de escrita que levaram às produções coletadas foram feitas pela professora em sala, tendo em vista o trabalho pedagógico planejado com a coordenação da escola, não tendo sido controlados previamente contextos para desenvolvimento desta pesquisa. 
A seguir, abordaremos as questões teóricas que deram embasamento ao trabalho, discutindo-se a perspectiva teórica no que diz respeito à sílaba, para, em seguida, abordar conceitos da nasalidade em Português e ortografia. Por fim, trataremos da conceituação de escrita para argumentar que as grafias não-convencionais da coda nasal são indícios do cruzamento entre práticas sociais orais/faladas e práticas sociais letradas/escritas (CORRÊA, 2004).

\section{Sílaba}

A sílaba pode ser vista sob o ponto de vista fonético, pelo qual se podem observar suas características físicas, e fonológico, pelo qual se podem observar suas características simbólicas e estruturais.

Cagliari (2009) afirma que, de um ponto de vista fonético, a sílaba pode ser vista como o resultado de movimentos musculares realizados sob pequenos jatos de ar que saem dos pulmões e, portanto, como o primeiro parâmetro articulatório a ser ativado na produção de um enunciado. Ainda de acordo com o autor, é possível reconhecer três partes nesse movimento: intensificação da força muscular; limite máximo de força atingido e, por fim, uma redução progressiva da força muscular. Sendo assim, é possível observar três partes na sílaba: duas periféricas e uma parte central (núcleo), a qual corresponde ao elemento de maior sonoridade da sílaba. Segundo Cagliari (2009), as sílabas são o suporte da fala e são preenchidas por segmentos fonéticos; cada língua tem um modo de preencher as sílabas em função das necessidades estruturais.

Com relação à perspectiva fonológica, existem dois modelos de descrição e explicação da sílaba: os lineares, segundo os quais a sílaba é formada por três constituintes autônomos, ou seja, todos os elementos da sílaba estão no mesmo plano estrutural; e os não lineares, segundo os quais os constituintes que compõem a sílaba não estão no mesmo plano estrutural. Neste trabalho, optamos pelo modelo não linear defendido por Selkirk (1982), pois, além dos segmentos estarem sujeitos a processos distintos a depender da posição que ocupam na sílaba, adotamos a posição, como será visto à frente, de que, no processo de produção escrita, algumas posições da sílaba oferecem maior complexidade ao escrevente.

Os dados de escrita serão interpretados como evidência de que a sílaba é uma unidade fonológica cujos elementos se organizam hierarquicamente. De acordo com a teoria assumida, a estrutura interna da sílaba possui uma organização hierárquica universal. Nessa concepção, a sílaba possui dois constituintes imediatos, o onset (ataque) e a rima (compreende os nós de núcleo e coda).

O foco desta pesquisa é justamente a posição de coda silábica, segundo a proposta de Selkirk (1982). De acordo com Cagliari (2009), do ponto de vista fonético, a posição de coda silábica corresponde a um momento de redução progressiva da força muscular, o que pode tornar os segmentos que ocupam esta posição menos audíveis e perceptíveis. Já do ponto de vista fonológico, pode-se dizer que a coda não é um constituinte imediato da sílaba, mas uma ramificação de um constituinte. Essa posição da sílaba não é preenchida em todas as línguas do mundo e, nas línguas em que existe, há aumento da complexidade da estrutura silábica, devido às fortes restrições quanto a seu preenchimento. 


\section{Nasalidade em português e ortografia}

Camara Jr. (1970) afirma que a nasalidade vocálica se diferencia em fonêmica (foco dessa pesquisa) e fonética. No primeiro caso, a nasalidade é contrastiva, a presença ou ausência de nasalação gera mudança de significado, como se observa em "junta" / "juta". No segundo caso, a nasalidade é proveniente da assimilação da consoante nasal da sílaba seguinte, nesse caso não tem mudança de sentido, como em "c[ã]mada".

Na literatura linguística, no que diz respeito à nasalidade contrastiva, não há consenso no que tange a seu estatuto fonológico. A discussão teórica a respeito do tema refere-se principalmente a dois argumentos. O primeiro é que os sistemas linguísticos apresentariam vogais nasais, o segundo é que a nasalidade resultaria de vogal oral seguida de elemento nasal. Neste estudo, considera-se que a representação fonológica de uma vogal nasal envolve vogal oral seguida de elemento nasal. No português, para representar a nasalidade ortograficamente, é preciso dois elementos gráficos: um que representa o segmento vocálico e outro que representa o traço nasal.

Na ortografia do Português, há quatro maneiras de representar a nasalidade, são elas: as letras $<\mathrm{m}>\mathrm{e}<\mathrm{n}>\mathrm{em}$ posição de início ("mata, nata") e de final de sílaba ("bambu, banco"); o til na última sílaba da palavra ("manhã"); o dígrafo <nh $>$ ("minha") em início de sílaba. Além disso, há casos em que ocorre a nasalização da vogal por contiguidade da consoante nasal na sílaba seguinte ("cama, cana, banha"). Essa nasalização da vogal, resultado de um processo de assimilação, não é representada ortograficamente.

No que diz respeito à posição de coda silábica, objeto desta pesquisa, constata-se que a nasalidade é representada pelos grafemas $<\mathrm{m}, \mathrm{n}>$ e pelo diacrítico $<\sim>$. Nesses três casos, há a nasalização da vogal da sílaba em que a coda é nasal, sem ocorrer necessariamente a articulação de uma consoante nasal. Essa característica difere das nasais em posição de ataque silábico, pois, nessa posição, cada uma das consoantes representa um segmento consonantal distinto que leva à distinção de palavras, a saber: $<\mathrm{m}>$ representa uma consoante labial ("amo"); $<$ n>, uma consoante alveolar ("ano"); $<$ nh>, uma consoante palatal ("anho").

O uso de cada uma dessas possibilidades de registro da nasalização da vogal em fim de sílaba depende de regras contextuais. É o caso do emprego de $<\mathrm{m}>$ em fim de sílaba ante /p/ e /b/ (“campo, bomba") e em fim de sílaba que coincide com fim de palavra ("bom, tem"). O emprego de $<\mathrm{n}>$ também ocorre em fim de sílaba nos contextos complementares aos da letra $<\mathrm{m}>$, isto é, $<$ n $>$ é empregado em fim de sílaba quando diante das demais consoantes do Português. Em algumas poucas palavras, $<\mathrm{n}>$ é empregada em fim de palavra, como em "hífen”. Por fim, $<\sim>$ apenas é empregado em sílabas em fim de palavra ("lã, maçã”).

\section{A heterogeneidade da escrita}

Consideramos neste trabalho o caráter heterogêneo de constituição de escrita, assim como Corrêa (2004). Defende-se, portanto, que, na análise de dados de escrita, é preciso considerar o entrecruzamento entre práticas de oralidade e práticas de letramento. Entende-se as grafias não-convencionais da coda nasal como marcas da heterogeneidade da escrita. Segundo Corrêa (2001), a heterogeneidade da escrita deve ser vista como constitutiva da escrita, interior a ela, e não como uma característica pontual e acessória. De acordo com essa concepção, não se trata de uma interferência do oral no escrito, mas de uma íntima relação entre fatos linguísticos (falado/escrito) e práticas sociais (orais/letradas), portanto, a escrita constitui-se pelo encontro entre práticas sociais do 
oral/falado e do letrado/escrito. Ainda para Corrêa (2001, 2004), a escrita deve ser entendida como processo e não como produto, ao considerá-la em seu processo de produção, além da relação entre oralidade e letramento, busca-se a relação entre sujeito e a linguagem, levando em consideração as representações que o escrevente constrói sobre a sua escrita, sobre o interlocutor e sobre si mesmo.

Para Corrêa (2001, 2004), existem três modos de reconhecimento da heterogeneidade da escrita, são eles: (1) aspectos da representação gráfica; (2) pela heterogeneidade da língua; (3) pela circulação dialógica do escrevente no momento da produção do texto escrito. Em (1), a heterogeneidade é reconhecida pela oscilação que o escrevente revela entre a representação dos sons que produz em sua variedade linguística falada e a convenção ortográfica (neutralização das variações) ensinada pela escola. Em (2), reconhece-se a heterogeneidade pelo fato de a escrita ser também considerada um modo de enunciação, assim como a fala. Por fim, em (3), é possível reconhecer a heterogeneidade da escrita a partir de três eixos nos quais os escreventes circulam no processo de produção de seu texto: o eixo da representação que o escrevente faz sobre o que imagina ser a gênese da escrita; o eixo da representação que o escrevente faz sobre o que imagina ser o código escrito institucionalizado; e o eixo da dialogia com o já falado/escrito.

Sendo assim, o produto escrito aparece como o resultado do trânsito do escrevente por diferentes práticas de linguagem, tanto orais quanto letradas. Dessa forma, as marcas de escrita que se relacionam às grafias não-convencionais da coda nasal seriam indícios desse cruzamento entre práticas sociais orais/faladas e práticas sociais letradas/escritas.

\section{Exposição dos resultados}

Para exposição dos resultados, organizamo-los em função dos objetivos que orientam o desenvolvimento da investigação exposta neste artigo. Inicialmente, abaixo, apresentamos as categorias de que nos utilizamos para classificar os registros identificados: não registro da coda nasal, que inclui duas possibilidades: (a) quando há registro não convencional de sílabas $\mathrm{CV}$ e (b) quando há registro de sílabas $\mathrm{CV}$, não sendo identificados, nesses casos, registros de sílabas com coda. Os registros escritos do Quadro 1 foram produzidos por um sujeito masculino ao longo do primeiro ano do EF.

Quadro 1. Registros de coda nasal menino

\begin{tabular}{|l|l|l|l|}
\hline \multicolumn{2}{|c|}{ Não registro da coda nasal } & \multicolumn{2}{c|}{ Registro da coda nasal } \\
\hline Não registro CV & Registro de CV & Não Convencional & Convencional \\
\hline APOO; EIOA; & BEGALA; XITILI; & BÃODERINHA; & CANGICA; LENCINHO; \\
OAOIK; AVTA & DETE; BATEDO; & REFIGERÃOTE; & COM (5X); QUEM; UM \\
& VETO; & QUÃOTA; COÃO; & (5X); MANTEIGA; \\
& CAZAMETO; & DONHETE; & PASSANDO; \\
& PRETEDE; DETRO & FAMTAMAS; & POMBINHA; BRANCA; \\
& $(2 X)$ & ESCOMDIDO (3X); & FAZENDO; LAVANDO; \\
& & MÃOTEGA; & BRANCO; MANDEI \\
& & HOMEN; LINPA & (2X); ENTRAR; SENTA; \\
& & DENTE \\
\hline
\end{tabular}

A partir da classificação das ocorrências, conforme exemplificado no Quadro 1, identificamos, por meio da Tabela 1, como se dá a distribuição dos tipos de ocorrências por sujeito. 
Tabela 1. Ocorrências de dados por sujeito

\begin{tabular}{|c|c|c|c|c|c|c|}
\hline \multirow[b]{2}{*}{ Sujeito } & \multicolumn{2}{|c|}{ Não registro da coda } & \multicolumn{2}{|c|}{ Registro da coda nasal } & \multicolumn{2}{|c|}{ Totais } \\
\hline & Não reg. CV & Reg. CV & Não conv. & Conv. & $\mathrm{N}^{\mathrm{o}}$ & $\%$ \\
\hline M1 & 4 & 2 & 10 & 33 & 49 & 0,12 \\
\hline M2 & 2 & 5 & 3 & 43 & 53 & 0,13 \\
\hline M3 & 3 & 15 & 13 & 21 & 52 & 0,12 \\
\hline M4 & 4 & 6 & 12 & 25 & 47 & 0,11 \\
\hline F1 & 4 & 1 & 7 & 41 & 53 & 0,13 \\
\hline F2 & 2 & 2 & 12 & 37 & 53 & 0,13 \\
\hline F3 & 0 & 2 & 5 & 45 & 52 & 0,12 \\
\hline F4 & 1 & 5 & 7 & 30 & 43 & 0,10 \\
\hline Totais & 20 & 38 & 69 & 275 & 402 & 0,96 \\
\hline
\end{tabular}

Por fim, apresentamos gráfico de ocorrências desses tipos de registros ao longo do EF para os oito sujeitos analisados. São informados os tipos de registros em função da produção escrita de modo a ser possível visualizar quando ocorre cada tipo de registro.

Gráfico 1. Percurso dos sujeitos

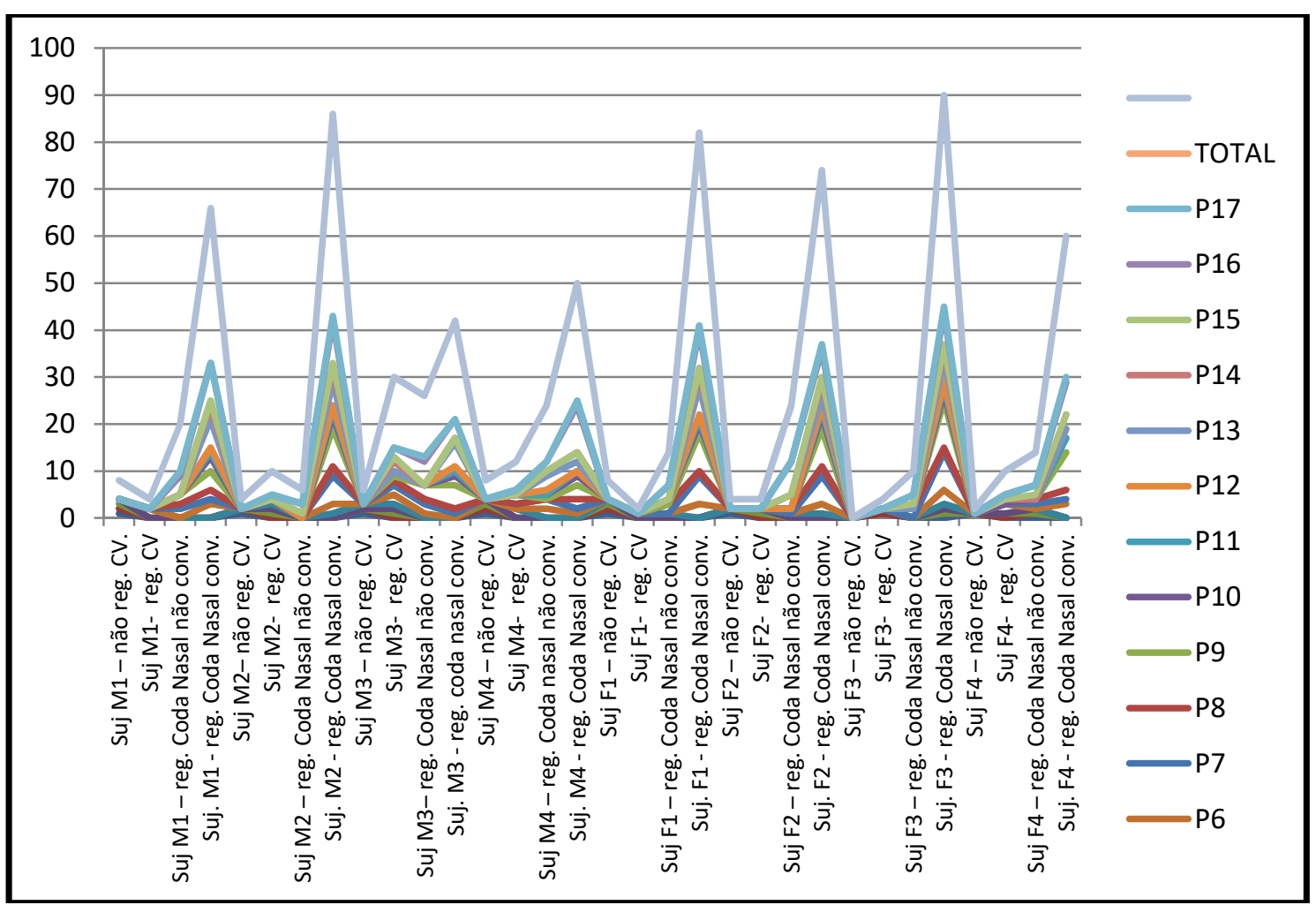

É possível identificar a tendência de os sujeitos grafarem sílabas CV não convencionalmente nas primeiras produções e, em seguida, registrar a sílaba CV. Já no segundo semestre, identifica-se a tendência em haver registros não convencionais da coda nasal que flutuam com o registro convencional. 


\section{Análise dos resultados}

Observa-se, primeiramente, que em todas as figuras não são registradas todas as posições de ataque e núcleo silábicos, sendo a coda uma dentre outras posições não registradas. Exemplo de não registro da sílaba CV: "qcgica" (cangica). Em seguida, há grafias em que são registradas as posições de ataque e núcleo silábicos, mas ainda não há registro da coda. Exemplo de registro da sílaba CV sem coda nasal: "doete" (doente), "fermeto" (fermento). Posteriormente, no segundo semestre do ano letivo, observa-se a tendência, para todos os sujeitos, tanto o registro não convencional da coda nasal, como também o registro convencional da coda nasal. Sobre os registros que representam a nasal, embora não seja empregada a grafia convencional, há o registro de coda com consoante nasal: "emtra", "linpa". Também há registros de base fonética de realização da coda nasal, sendo representada por uma vogal, tendo, portanto, o registro de vogal da rima e acrescentada uma vogal fonética: "seita" (senta), "rerigraete" (refrigerante). Nesse grupo, também incluímos registros não convencionais da vogal da sílaba com coda nasal: "boderinha" (banderinha). Nesse caso, a troca de $<a>$ por $<0>$ tem motivação, possivelmente, na tentativa de registro da qualidade fonética da vogal nasal [ã].

Sendo assim, todos os tipos de registros não convencionais da coda nasal que observamos foram consoante nasal $<\mathrm{m}, \mathrm{n}>\operatorname{com} 37$ ocorrências; dígrafo $<\mathrm{nh}>\operatorname{com}$ duas ocorrências; vogal $<$ i, e $>$ com oito ocorrências; ditongo nasal $<$ ão $>$ com sete ocorrências e os classificados por outros com 14 ocorrências, sendo eles: "denuro" (dentro) (2x); "revrigeãronte" (refrigerante); "csãtili" (chantili); "donete" (doente); "chãtili" (chantili); "boderinha" (bandeirinha); "co" (com); "prtrede" (pretende); "der" (dentro); "dertoro" (dentro); "baterdo" (batendo); "lavedo" (lavando); "melelnsi" (melancia).

No registro não convencional de nasal com consoantes $<\mathrm{m}, \mathrm{n}>$, observa-se que a criança não domina a regra contextual de emprego de $<\mathrm{m}>$ e $<$ n $>$, mas já sabe que a nasalidade é representada por consoante nasal em um vasto conjunto de palavras. $\mathrm{O}$ registro não convencional de coda nasal com dígrafo $<$ nh $>$ representa uma nasal palatal que tem o traço [alto] e, nas palavras encontradas, é possível supor que o dígrafo represente tanto a nasalidade quanto o traço [alto] da vogal [i] que se realiza foneticamente. Cf: "donhete" (“doente") para [doe)i] te. Já o registro não convencional de coda nasal com vogal $<\mathrm{i}$, e $>$ mostra que, no lugar da consoante nasal, há o registro da vogal fonética [i] para as palavras em que a vogal silábica é [e]. Na maioria dos dados, não há registro da nasalidade: "deite" "deinte" (dente).

$\mathrm{O}$ registro não convencional de coda nasal com o ditongo $<$ ão $>$ mostra que no lugar da consoante nasal, há o registro da vogal $<0>$ e a nasalidade é grafada com $<\sim>$. Ex. "mãotega" (manteiga). Esses registros predominam em sílabas em que a rima é [a]+coda nasal: "manteiga". Interpretamos como indício da busca da criança por registrar a qualidade fonética da vogal [ã]. Os registros não convencionais de coda nasal menos frequentes classificados como outros são registros únicos encontrados na amostra considerada. Em "boderinha" (bandeirinha) e "lavedo" (lavando), há tentativa de registro da qualidade fonética de [bã] e [vã], respectivamente. A grafia da vogal [ã] passa a ser de uma vogal mais recuada e mais alta em relação à [a] e, das letras de que dispõe, a criança registra com a letra $<0>$ em "boderinha"; já a vogal da vogal [ã] passa a ser de uma vogal anterior mais alta em relação à [a], ao registrar com a letra $<\mathrm{e}>$ em "lavedo" essa qualidade fonética da vogal nasal. 
Em "melelnsi" (melancia), há uma tentativa de registro da qualidade fonética de [1ã], sendo assim, há o registro da vogal $<\mathrm{e}>$ no lugar $\mathrm{de}<\mathrm{a}>$ seguido do segundo registro da consoante do ataque $<\mathrm{l}>$ e da nasalidade por meio de $<\mathrm{n}>$. É forte indício de a criança estar trabalhando com hipóteses sobre possibilidades de registro da vogal e da coda nasal. Em "csãtili" (chantili); "chãtili" (chantili); "cõ" (com), a criança grafa ( ). Já em "prtrede" (pretende), o $<\mathrm{r}>\mathrm{em}$ "ter" representa a coda, mas a letra migrou da coda para o ataque. Em "revrigeãronte" (refrigerante), a vogal não-convencional + coda $<$ on $>$ precedida pela vogal convencional com til $<\tilde{a}>$ mostra dupla marca da vogal nasal. Em "der; dertoro" (dentro); "baterdo" (batendo), ocorre a troca $<\mathrm{n}>$ por $<\mathrm{r}>$. Em "denuro" (dentro), a grafia convencional de $<$ den $>$ seguida de troca " $t$ " por " $u$ " resulta em estruturas CV. E por fim, em "donete" (doente), a grafia não-convencional da vogal $<$ o $>$ (qualidade vocálica) e inversão de posição de $<\mathrm{e}>\mathrm{e}<\mathrm{n}>$ resulta em estruturas $\mathrm{CV}$.

\section{Considerações finais}

Os registros escritos não convencionais dão indícios de haver ancoragem da criança na realização fonética da vogal da sílaba com coda nasal (registros como "seita"), e também em informações ortográficas sobre a representação da nasalidade em fim de sílaba (registros como "linpa", "emtra"); e em ambos os tipos de informação (fonética e ortográfica) para representar a nasalidade (registros como "deinte", "avenhca"). Portanto, os registros analisados dão indícios do trânsito do escrevente tanto por características dos enunciados falados quanto por características ortográficas para representar a coda nasal, sendo que o trânsito dos escreventes por aspectos fonéticos e ortográficos da representação da nasalidade do português dá pistas de como se dá a relação entre fala e escrita no processo de aquisição da escrita.

Conhecer como se caracteriza esse trânsito dos escreventes é relevante para a prática pedagógica relativa à alfabetização de crianças, na medida em que mostra que crianças que não registram todas as posições da sílaba, sendo a coda uma dentre outras posições não registradas, "qcgica" (cangica), assim como as que registram as posições de ataque e núcleo silábicos, mas ainda registram a coda, "doete" (doente), "fermeto" (fermento), ou então, as que passam a oscilar entre o registro não convencional e convencional da coda nasal estão sinalizando como se dá o processo de escrita, e, dessa forma, não se pode olhar para tais registros como negativos, e sim como processo de aprendizagem. Sendo assim, de acordo com Corrêa (2001), deve-se levar a sério a constituição heterogênea da escrita e, portanto, professores devem estar cientes de que esses casos não podem ser tratados como interferência da oralidade no produto escrito, mas sim como um processo de produção escrita do aluno.

\section{REFERÊNCIAS}

BISOL, L. A nasalidade, um velho tema. DELTA, São Paulo, v. 14, n. especial, p. 24-46, 1998.

A sílaba e seus constituintes. In: NEVES, M. H. M. Gramática do Português

Falado. v. 7. Campinas: Editora da UNICAMP, 1999. p. 701-742. 
. Estudo sobre a nasalidade. In: ABAURRE, M. B. M.; RODRIGUES, A. C. S. (Org.). Gramática do Português Falado. v. 8. Campinas: Editora da UNICAMP, 2002. p. 501-535.

BORDUQUI, C. L. B. As vogais pretônicas no noroeste paulista: estudo da vogal/e/ nas sílabas VC em início de palavra. In: $58^{\circ}$ Seminário do GEL, 2010, São Carlos. $58^{\circ}$ Seminário do Gel, 2010.

CAGLIARI, L. C. Um pouco da história da nasalidade: da ortografia para a fonética e fonologia. In: X Congresso da AIL: Lusofonia tempo de reciprocidades, 2008. Resumos. Funchal: Funchal 500 Anos, E. E. M., v. 1, p. 1-16, 2008. Elementos de fonética do Português Brasileiro. São Paulo: Paulistana, 2009.

CAMARA JR, J. M. Problemas de lingüistica descritiva. 3. ed. Petrópolis: Vozes, 1970. CORRÊA, M. L. G. Letramento e heterogeneidade da escrita no ensino de português. In: SIGNORINI, I. (Org.). Investigando a relação oral/escrito e as teorias do letramento. Campinas: Mercado de Letras, 2001. p. 135-166. 2004. O modo heterogêneo de constituição da escrita. São Paulo: Martins Fontes,

MIRANDA, A. R. M. A grafia de estruturas silábicas complexas na escrita de crianças. In: PINHO, S. Z. (Org.). Formação de Educadores: o papel do educador e sua formação. v. 1. São Paulo: Editora da UNESP, 2009. p. 409-426.

SELKIRK, E. O. The Syllable. In: HULS, V. der; SMITH, N. (Ed.). The Structure of Phonological Representations (Part II). Dordrecht: Foris Publication, 1982.

WETZELS, W. L. Contrastive and allophonic properties of Brazilian Portuguese vowels. In: KIBBEE, D.; WANNER, D. (Ed.). New Analyses in Romance Linguistics. Amsterdam: J. Benjamins, 1988.

Recebido em: 17/10/2016

Aprovado em: 27/01/2017 